\title{
Identification of a novel zinc finger protein binding a conserved element critical for Pit-1-dependent growth hormone gene expression
}

\author{
Steven M. Lipkin, ${ }^{1,2}$ Anders M. Näär, ${ }^{1,3}$ Kristin A. Kalla, ${ }^{4}$ Ram A. Sack, ${ }^{1,4}$ and \\ Michael G. Rosenfeld ${ }^{1,4}$ \\ ${ }^{4}$ Howard Hughes Medical Institute, ${ }^{1}$ Eukaryotic Regulatory Biology Program, ${ }^{2}$ Graduate Program in Neurosciences, \\ ${ }^{3}$ Graduate Program in Molecular Pathology, University of California, San Diego, School and Department of Medicine, \\ La Jolla, California 92093-0648 USA
}

The growth hormone $(\mathrm{GH})$ and prolactin genes require the pituitary-specific POU domain transcription factor Pit-1 for their activation. However, additional factors are necessary for the effective expression of these genes. Analysis of evolutionarily conserved sequences in the proximal GH promoter suggests the critical importance of one highly conserved element located between the two Pit-1 response elements. Mutation of this site decreases expression of a transgene in mice $>100$-fold. We have identified a major activity binding to this site as a novel member of the Cys/His zinc finger superfamily, referred to as $\mathrm{Zn}-15$. The $\mathrm{Zn}-15 \mathrm{DNA}$-binding domain comprises three zinc fingers separated by unusually long linker sequences that would be expected to interrupt specific DNA site recognition. Zn-15 synergizes with Pit-1 to activate the GH promoter in heterologous cell lines in which this promoter is only minimally responsive to Pit-1 alone. Our data suggest that functional interactions between the tissue-specific POU domain factor Pit-1 and this novel zinc finger factor binding to an evolutionarily conserved region in the GH promoter may constitute an important component of the combinatorial code that underlies the effective expression of the GH gene.

[Key Words: Pit-1; growth hormone; zinc finger; pituitary; transgenic]

Received May 3, 1993; revised version accepted June 24, 1993.

Defining the molecular mechanisms by which select combinations of transcriptional regulators cooperate to regulate tissue-specific gene expression in discrete cell types is a central issue in mammalian development. The growth hormone $(\mathrm{GH})$ gene, expressed solely in the somatotroph cell type in the anterior pituitary, has been studied extensively as a model of tissue-specific gene expression (Voss and Rosenfeld 1992). The proximal GH promoter is capable of targeting somatotroph-specific gene expression and contains two pituitary-specific promoter cis-active elements (Nelson et al. 1986; Bodner and Karin 1987; Nelson et al. 1988; Sharp and Cao 1990). The characterization of a protein that binds to and activates these cell-specific cis-active elements permitted the cloning of Pit-1 (Ingraham et al. 1988; Bodner et al. 1988), a POU domain transcription factor (He et al. 1989) expressed soley in pituitary somatotrophs, lactotrophs, and thyrotrophs. During rat embryogenesis, Pit-1 mRNA is initially detected on e15, 24-36 hr prior to $\mathrm{GH}$ and PRL gene activation (Simmons et al. 1990; Dolle et al. 1990). The critical importance of Pit-1 for the survival of somatotrophs, lactotrophs, and thyrotrophs, and for $\mathrm{GH}$ gene expression, is illustrated by Snell and Jackson dwarf mice, which possess Pit-1 genomic mutations and lack these cell types in the mature animal ( $\mathrm{Li}$ et al. 1990). Furthermore, the physiological importance of Pit-1 for GH and PRL transcription has been demonstrated by the identification of human dwarfs who are deficient in both PRL and GH and possess either single-amino-acid substitutions in the Pit-1 POU domain or the introduction of a premature stop codon. (Ohta et al. 1992; Pfäffle et al. 1992; Radovick et al. 1992; Tatsumi et al. 1992).

However, the activation of GH, PRL, and TSH $\beta$ target genes by Pit-1, and the expression of each in distinct cell types, requires the coordinate actions of factors additional to Pit-1. For example, in transient transfection, the prolactin distal enhancer is effectively stimulated by Pit-1 only in combination with the ligand-activated estrogen receptor (Day et al. 1990; Simmons et al. 1990). For the rat $\mathrm{GH}$ gene, $\mathrm{T}_{3}$ has been suggested to be an important positive regulator. In pituitary tumor cells, $T_{3}$ causes a dramatic increase in newly initiated rat $\mathrm{GH}$ mRNA transcripts (Evans et al. 1982). The identification of a $T_{3}$ response element $\left(T_{3} R E\right)$ in the rat $G H$ promoter suggests that $T_{3}$ mediates its effects through the binding of $T_{3}$ receptors to this promoter /Glass et al. 1987; Brent 
et al. 1989|. However, the sequence of the $T_{3} R E$ is not conserved in the human GH promoter; in transfection, $\mathrm{T}_{3}$ negatively regulates human $\mathrm{GH}$ (Zhang et al. 1992), suggesting that it may not be a required component of $\mathrm{GH}$ activation.

Mapping of the critical sequences for expression in transgenic mice revealed that the proximal $180 \mathrm{bp}$ of the $\mathrm{GH}$ promoter contained all of the information necessary to target expression to the anterior pituitary gland (Lira et al. 1988,1993). Therefore, we systematically examined evolutionarily well-conserved sequences exclusive of the Pit- 1 and $\mathrm{T}_{3}$ response elements in the proximal GH promoter and tested the effects of their disruption on transcription in a somatotroph cell line (GC); we found that the functionally most important sequence $(-110$ to -95) lies between the proximal and distal Pit-1-binding sites and is unusually well conserved across species. When this sequence was mutated in the context of the proximal 320 bp of the rat GH promoter as a transgene, promoter activity was impaired $>100$-fold. On the basis of the functional importance of this element in vivo, we identified a major pituitary cell-binding activity to this site, referred to as Zn-15 (pronounced Zen-15), a novel transcription factor possessing a structurally unusual DNA-binding domain consisting of three Cys $\mathrm{X}_{2-4}$ Cys $\mathrm{X}_{11-16} \mathrm{HisX}_{3-6} \mathrm{His}$ zinc fingers in the context of 15 potential zinc fingers of similar sequence. These three zinc fingers are separated by surprisingly extensive linker sequences that would be predicted to interrupt their ability to form a unitary DNA-binding domain. Zn15 synergizes with Pit- 1 to activate the GH promoter in heterologous cell lines in which this promoter is only minimally responsive to Pit- 1 alone. These data suggest that synergistic interactions between Pit-1 and this novel zinc finger factor binding an evolutionarily conserved region in the $\mathrm{GH}$ promoter may be required for the effective activation of the $\mathrm{GH}$ gene.

\section{Results}

The GH Z box is required for effective expression of the GH promoter

Because the proximal $180 \mathrm{bp}$ of the rat $\mathrm{GH}$ promoter contains sufficient information to target pituitary-specific expression in transgenic mice, we hypothesized that evolutionarily conserved sequences in this promoter region additional to the Pit-1-binding sites were likely to contribute to effective expression of the $\mathrm{GH}$ gene. We therefore mutated three well-conserved sites in this promoter region and functionally evaluated the effects of these mutations in transiently transfected rat pituitary tumor cells (GC) (Fig. 1A). Mutation of two conserved sequences (a putative AP-2-binding site $(-159 /-148)$ (Lefevre et al. 1987) and a putative Spl site $(-142 /-130)$ (Lemaigre et al. 1990; Schaufele et al. 1990) had little effect (Fig. 1B). In contrast, mutation of a third conserved sequence $(-110 /-95)$ located between the proximal and distal Pit-1-binding sites markedly decreased activity (referred to as the GH Z box; Fig. 1A,C).
Previously, footprinting experiments using GC cell extracts had revealed the presence of DNase I hypersensitive sites over this sequence, suggesting that a binding activity to this site might exist in somatotrophs (Mangalam et al. 1989; H. Mangalam, pers. comm.).

To evaluate the importance of the GH Z box in vivo, pedigrees of transgenic mice carrying either a wild-type or mutated $\mathrm{GH} \mathrm{Z}$ box in the context of the proximal 320-bp rat $\mathrm{GH}$ promoter fused to a human $\mathrm{GH}$ (hGH) reporter gene (Fig. 2A) were established, and the pituitary hGH content from these mice quantitated by radioimmunoassay. The GH Z box mutation in vivo resulted in a decrease of $>100$-fold in reporter gene expression (Fig. 2B). No ectopic expression of the hGH transgene was observed in any pedigree further characterized (Fig. 2C; data not shown). To confirm the dramatic effect of the GH Z box mutation on transgene expression, in situ hybridization was performed. Sections of adult anterior pituitary glands from mice carrying the wild-type GH promoter transgene showed intense hybridization signal compared with that observed in pituitaries from mice carrying the $\mathrm{GH} \mathrm{Z}$ box mutation when probed with a ${ }^{35}$ S-labeled oligonucleotide probe specific for hGH (Fig. 3). As expected, pituitaries from mice carrying either transgene construct hybridized strongly to a mouse $\mathrm{GH}$ (mGH)-specific probe (Fig. 3).

\section{Characterization and Cloning of the GH Z box- binding factor}

When a ${ }^{32} \mathrm{P}$-labeled oligonucleotide encompassing the GH Z box sequence was incubated with nuclear extracts prepared from a panel of pituitary and nonpituitary cell lines, a binding activity to the $\mathrm{GH} \mathrm{Z}$ box with identical mobility was observed in most lines examined, suggesting that the $\mathrm{GH} \mathrm{Z}$ box-binding activity was not tissue specific (Fig. 4A). This activity could be competed by addition of unlabeled $\mathrm{GH} \mathrm{Z}$ box oligonucleotide, but not other oligonucleotide sequences, to the binding reaction (data not shown). Electrophoretic mobility shift analysis (EMSA) assays using bacterially expressed Pit-1 incubated with the proximal 145 bp of the GH promoter with and without the GH Z box mutation showed that this mutation did not secondarily impair Pit-1 binding to its response elements (Fig. 4B).

The GH Z box site was used to screen rat pituitary and somatotroph cell (GC) $\lambda$ gt 11 expression libraries, and a clone that bound specifically to this site was further characterized. This clone contained partial sequences of a novel member of the superfamily of transcriptional regulators containing several $\mathrm{CysX}_{2-4} \mathrm{CysX}_{11-16} \mathrm{HisX}_{3-6} \mathrm{His}$ zinc fingers (Rhodes and Klug 1993). Multiple overlapping clones were isolated to obtain the full-length cDNA (Fig. 5). Stop codons in all three frames precede an ATG that initiates a $6.5-\mathrm{kb}$ continuous open reading frame (ORF) containing 15 putative $\mathrm{CysX}_{2-4} \mathrm{CysX}_{11-16} \mathrm{HisX}_{3-}$ 6His zinc fingers (Fig. 5). Because of this distinguishing structural feature, we call the protein $\mathrm{Zn}-15$.

$\mathrm{Zn}-15$ has no described gene homolog in any species. The full $\mathrm{Zn}-15$ ORF predicts a protein with a molecular 


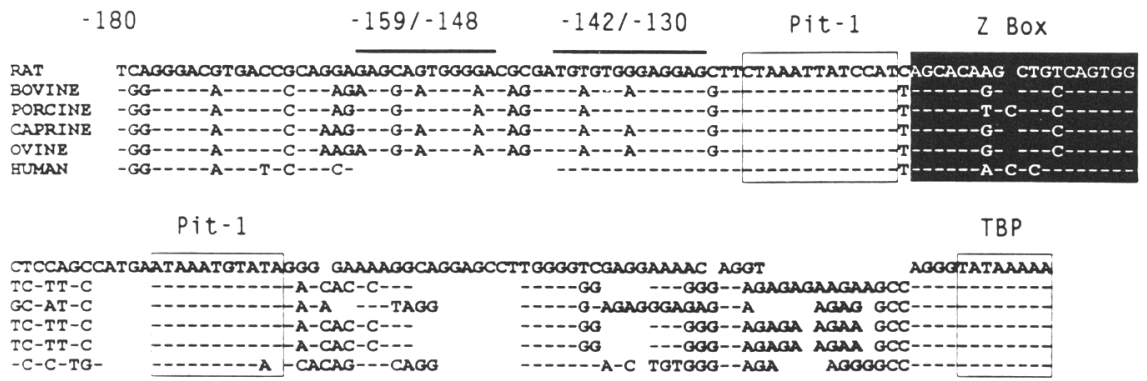

B

\section{LUCIFERASE ACTIVITY}

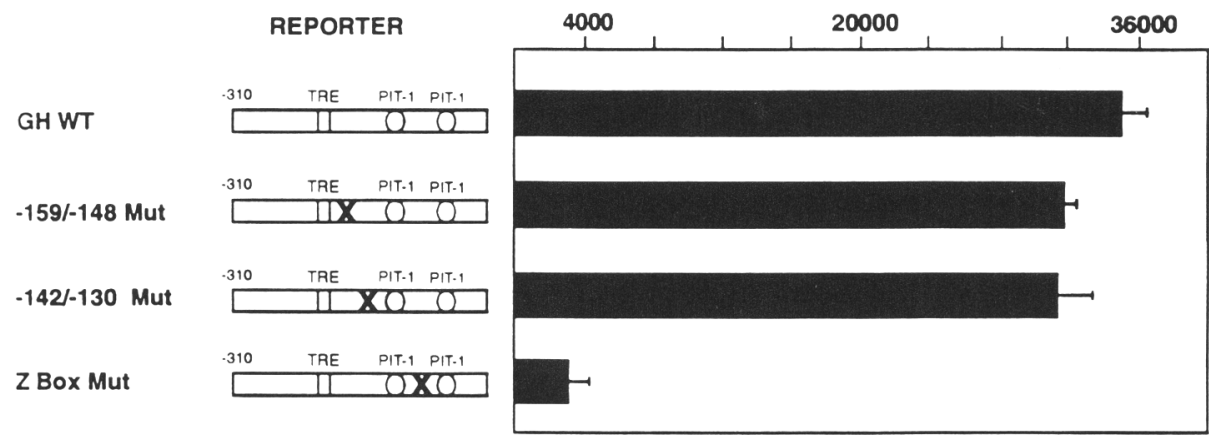

Figure 1. Identification of an evolutionarily conserved, functionally important site in the GH promoter $(-110 /-95)$. (A) Alignment of the proximal $\mathrm{GH}$ promoter sequences from rat, bovine, pig, goat, sheep, and human species. The three evolutionarily conserved regions further analyzed by mutation are deliniated either by a line $(-159 /-148$ and $-142 /-130)$ or reverse highlight $(-110 /-95 ; \mathrm{Z}$ box). The Pit- 1 and TATA box protein-binding sites are boxed. $(B)$ Transcriptional effects of the $-158 /-148,-142 /-130$, and $Z$ box $(-110 /-95)$ mutations on GH promoter activity in GC pituitary cells. Five micrograms of the wild-type or mutated proximal GH promoter $(-310$ to +08$)$ driving the expression of a luciferase cDNA

C

\section{Z BOX CONSENSUS}

SPECIES

RAT BOVINE

DORCINE

CAPRINE

OVINE

HUMAN

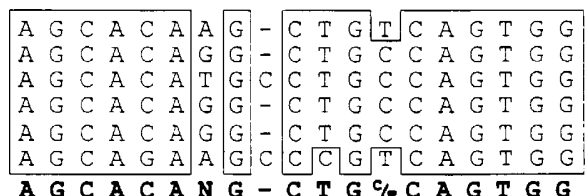

A $G$ G A $A$ C A A $A-C$ C T G T C A G T G G $A G C A C A G G-C$ T $C$ C $C$ C A G T G G

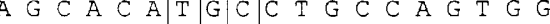

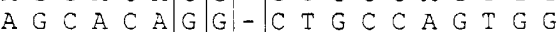
A G A A G G were transfected into GC cells as described previously (Nelson et al. 1988). Results are the average of triplicate determinations \pm S.E.M. similar results were obtained in five experiments of similar design. $(C)$ Derivation of a consensus $\mathrm{Z}$ box sequence.

mass of $240 \mathrm{kD}$. However, in vitro translation of the full coding sequence produces a protein that migrates on denaturing SDS-polyacrylamide gels with a mobility of $\sim 180 \mathrm{kD}$, in addition to a minor $75-\mathrm{kD}$ product (Fig. $6 \mathrm{C}$ ). To resolve this discrepancy between predicted and apparent molecular mass on SDS-polyacrylamide gels, we raised a polyclonal antisera reactive against the $\mathrm{Zn}-15$ carboxyl terminus. Western blot analysis of nuclear extracts made from rat somatotroph (GC) cells (Fig. 6C) revealed that antisera specific for $\mathrm{Zn}-15$ reacted specifically against a $180-\mathrm{kD}$ protein and also a $75-\mathrm{kD}$ protein that appears to represent a proteolytic product (Fig. 6C; data not shown). Because of the concordance between the size of in vitro-translated $\mathrm{Zn}-15$ and the higher molecular mass species present in cell extracts, we consider it likely that the full-length Zn-15 ORF migrates at a size anomalous to its predicted molecular mass. Aberrant electrophoretic behavior has also been observed for several other large members of the $\mathrm{CysX}_{2-4} \mathrm{CysX}_{11-}$
${ }_{16} \mathrm{HisX}_{3-6} \mathrm{His}$ class of transcription factors (Ruppert et al. 1990; Read and Manley 1992; Settleman et al. 1992).

Probing GC cell mRNA with a Zn-15 carboxy-terminal coding fragment revealed that the rat $\mathrm{Zn}-15$ mRNA is expressed as a single band of $\sim 7.4 \mathrm{~kb}$ in size (Fig. 6D). RNase protection analysis of a panel of rat tissues with an 863 bp fragment from the Zn-15 carboxy-terminal zinc finger cluster demonstrates that $\mathrm{Zn}-15 \mathrm{mRNA}$ is expressed in pituitary and nonpituitary tissues, including spleen, pituitary, and heart (Fig. 6E). Thus, unlike Pit-1, $\mathrm{Zn}-15$ expression is not restricted to the anterior pituitary gland.

Zn-15 possesses a DNA-binding domain consisting of three zinc fingers with extremely elongated linker sequences

A fragment encompassing six of the seven zinc fingers in 
A

GH WT

Z BOX MUT

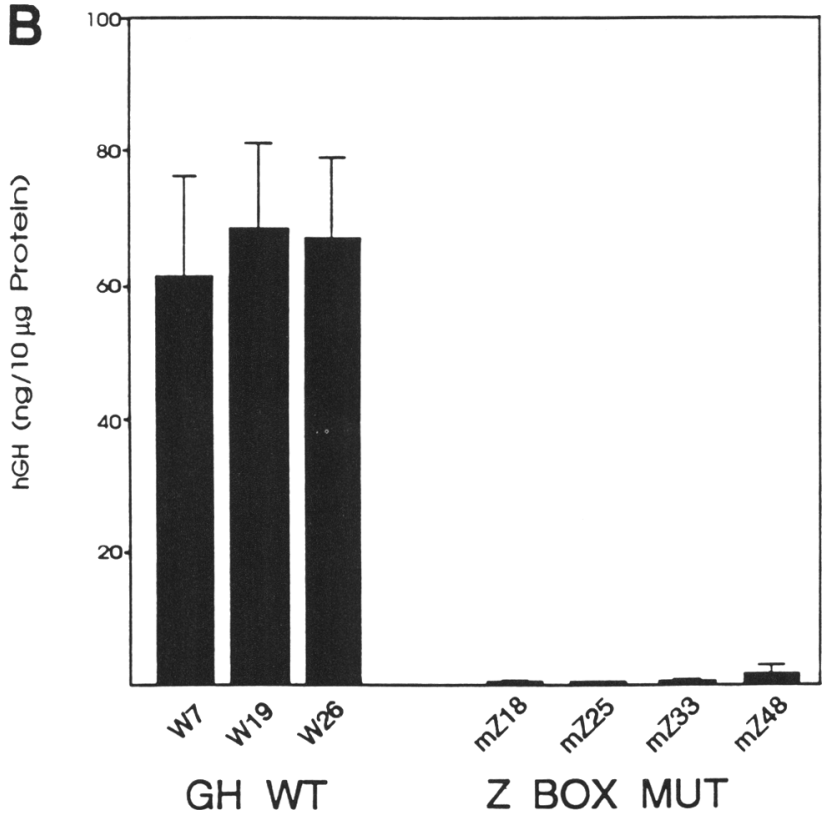

C

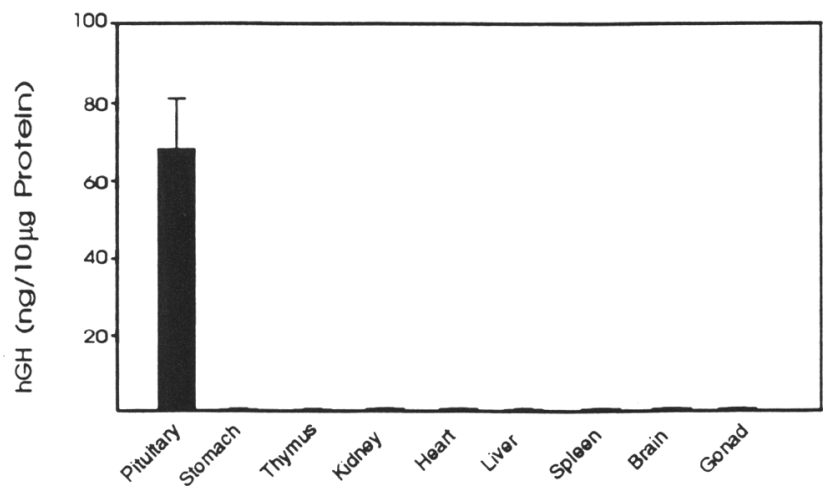

Figure 2. Functional analysis of the $\mathrm{GH} \mathrm{Z}$ box mutation in the expression of a transgene in mice. $(A)$ Depiction of the GH wildtype and $\mathrm{GH} \mathrm{Z}$ box mutant transgene constructs. The wild-type proximal GH promoter (GH WT) spanning from -320 to +08 relative to the start of transcription, and the the mutated $\mathrm{GH} \mathrm{Z}$ box $(-110 /-95)(Z$ BOX MUT) in the identical promoter context were fused to a human genomic $\mathrm{GH}$ reporter gene (hGH). (B) Quantitative analysis of GH WT and GH Z BOX MUT promoter-driven hGH transgene expression in the pituitary gland. The two promoter/hGH fusion constructs were injected into mouse oocytes; three separate lines of founder mice containing stably integrated copies of the GH WT construct (W7, W19, and W26), and four separate lines containing the Z BOX MUT construct $(\mathrm{mZ} 18, \mathrm{mZ25}, \mathrm{mZ33}$, and $\mathrm{mZ} 48$ ) were established and used for further analysis. Pituitary glands were excised from adult mice, and the hGH content was quantitated by radioimmunoassay (Nicholls Institute) after normalization for protein

(Bio-Rad). The expression levels of each transgenic line (nanograms of hGH/10 $\mu$ g of protein \pm S.E.M.) are, respectively, W7, $60.9 \pm 19.1$ $(n=4) ; \mathrm{W} 19,68.0 \pm 13.0(n=6) ; \mathrm{W} 26,66.6 \pm 12.3(n=3) ; \mathrm{mZ} 18,0.1 \pm 0.1(n=8) ; \mathrm{mZ25}, 0.1 \pm 0.1(n=1) ; \mathrm{mZ33}, 0.37 \pm 0.2$ $(n=3) ; \mathrm{mZ48}, 1.58 \pm 1.2(n=8)$. (C) Tissue specificity of GH WT transgene expression. A panel of nonpituitary tissues from all transgenic lines further character-ized were excised from adult mice and quantitated for hGH content. Shown are representative results from a mouse carrying the GH WT transgene (W19 pedigree).

the carboxy-terminal cluster encoded in the original $\lambda$ gt 11 phage insert was expressed in bacteria $(\mathrm{Zn}-15 \mathrm{C} 6)$, and the specificity of $\mathrm{Zn}-15$ binding to the $\mathrm{GH} \mathrm{Z}$ box was examined. Zn-15 C6 bound with high affinity to a ${ }^{32} \mathrm{P}$ labeled $\mathrm{GH} \mathrm{Z}$ box oligonucleotide but not to the mutated site that had been substituted for the $\mathrm{Z}$ box in the initial scanning mutagenesis of the $\mathrm{GH}$ promoter, nor to several other sites tested (Fig. 7A). Unexpectedly, we found that $\mathrm{Zn}-15$ can also bind with high affinity to the $\mathrm{T}_{3} \mathrm{RE}$ from the rat $\alpha$-myosin heavy chain gene $\left(\mathrm{MHC}_{3} \mathrm{RE}\right)$ but not to other $\mathrm{T}_{3}$ REs tested (Figure 7A). Alignment of the GH $\mathrm{Z}$ box and the $\alpha-M H C \mathrm{~T}_{3} \mathrm{RE}$ sequences shows a high degree of sequence identity (see Fig. 8C).

To determine which of these six zinc fingers are critical for binding to these two sites, a series of six mutant $\mathrm{Zn}-15$ C6 proteins were expressed in bacteria in which the first conserved histidine residue of each of the six fingers was mutated to a serine. Mutation of either fingers IX, X, or XI abolished all binding to the GH Z box while mutation of fingers XII, XIII, or XIV was without significant effect (Fig. 7B).The same mutations also abolished $\alpha M H C \mathrm{~T}_{3} \mathrm{RE}$ binding (data not shown). Therefore, zinc fingers IX, $\mathrm{X}$, and $\mathrm{XI}$ are each necessary for binding to both recognition elements. The cooperation of these three zinc fingers to form a unitary DNA-binding domain is somewhat unexpected in that the linker sequence between zinc fingers IX and $\mathrm{X}$ is 21 amino acids and the linker sequence between zinc fingers $\mathrm{X}$ and $\mathrm{XI}$ extends a full 143 amino acids. Previously, in all of the other zinc finger proteins whose DNA-binding abilities have been directly tested, only zinc fingers separated by short (usually 7 amino acids) linker sequences in tandem have been shown to cooperate to form a single DNAbinding domain. Because zinc loop fingers that are spaced widely are a common feature among members of this superfamily, our data suggest that such widely spaced fingers may contribute DNA-binding domains with DNA site specificity comparable to those of factors that contain tandem arrays of closely spaced zinc fingers.

To examine the ability of the amino-terminal six zinc fingers to bind DNA, this region of $\mathrm{Zn}-15$ was also expressed in bacteria (Zn-15 N6). Interestingly, several of the zinc fingers possess residues that are predicted to disrupt the ability of this structure to bind DNA (Pav- 
GH WT
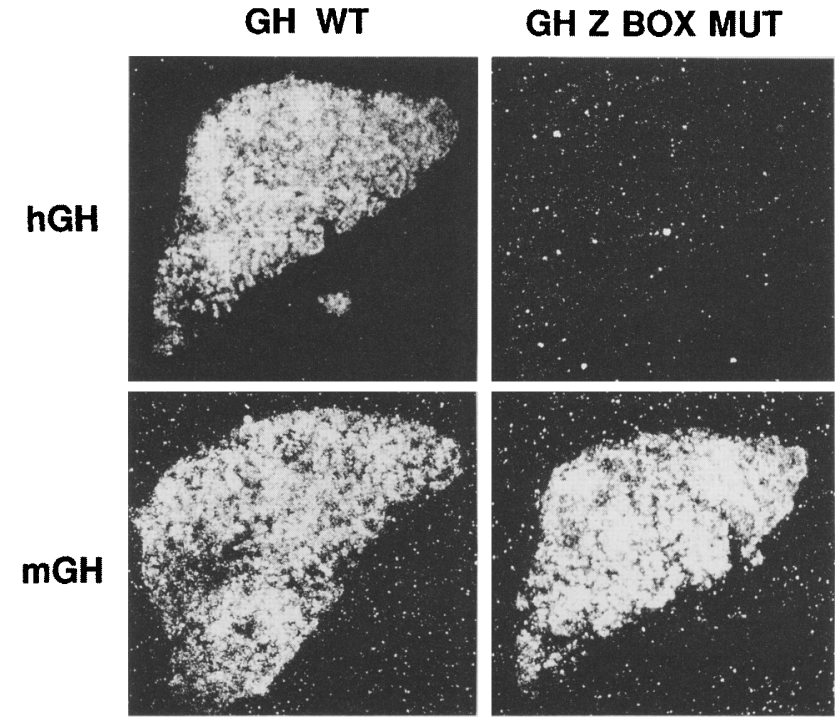

Figure 3. In situ hybridization analysis of hGH reporter gene expression in transgenic mice. Sagittal sections of pituitary glands from adult mice carrying either the wild-type GH promoter (GH WT; transgenic pedigree W26) or the identical construct carrying a GH Z box mutation (GH Z BOX MUT; transgenic pedigree $\mathrm{mZ18}$ ) were probed with ${ }^{35} \mathrm{~S}$-labeled oligonucleotide probes specific for either human (hGH) or mouse $(\mathrm{mGH})$ GH 3'-untranslated mRNAs. Depicted are dark-field photographs of $10 \mu \mathrm{m}$ sagittal pituitary sections at a $45^{\circ}$ angle. The photograph of the GH Z BOX MUT hybridization with the hGH-specific probe was exposed for a longer time relative to the other three hybridizations to allow visualization of the pituitary tissue section against the dark-field background.

letich and Pabo 1991): Finger I encodes an alanine instead of a large hydrophobic residue (Phe, Tyr, or Val) 2 amino acids before the first cysteine, and fingers II, V, and VIII contain proline residues that are predicted to disrupt the $\alpha$-helix preceding the first conserved histidine that recognizes DNA along the major groove. To determine whether the cluster of six amino-terminal zinc fingers were capable of binding to any DNA site with high affinity, binding to a ${ }^{32} \mathrm{P}$-labeled heterogenous 16-bp binding site containing all possible sequence combinations was examined in EMSA analysis (Fig. 7C). The $\mathrm{Zn}-15 \mathrm{~N} 6$ protein did not appear to bind detectably to the heterogenous binding site probe, whereas the $\mathrm{Zn}-15 \mathrm{C} 6$ protein clearly formed two strong protein-DNA complexes. Thus, despite the fact that fingers III, IV, and VI do conform to consensus Cys/His zinc finger amino acid sequences, we are unable to detect specific DNA binding by them in our assay.

\section{$\mathrm{Zn-15}$ is the dominant $G H \mathrm{Z}$ box-binding activity in a somatotroph cell line}

Methylation interference analysis using GC cell nuclear extract and bacterially expressed Zn-15 C6 showed that both activites generated an identical methylation interference pattern (Fig. 8A). These results suggest that a
Zn-15-like activity in somatotroph cells binds to the GH $\mathrm{Z}$ box. To determine further whether $\mathrm{Zn}-15$ represents the major binding activity to the GH $\mathrm{Z}$ box, gel shift analyses were executed using GC cell extract and antisera reactive against $\mathrm{Zn}-15$. Although preimmune sera had no apparent effect, addition of $\alpha \mathrm{Zn}-15$ antisera abolished the the major binding complex (Fig. 8D). These results are consistent with the methylation interference analysis, suggesting that $\mathrm{Zn}-15$ represents a major $\mathrm{GH} \mathrm{Z}$ box-binding activity in cells expressing the endogenous GH gene.

\section{$\mathrm{Zn-15}$ is a trans-activator that synergizes with Pit-1 to activate the GH promoter}

As determined by EMSA analysis, GH Z box-binding activity is low in African green monkey kidney cells (CV-1) (Fig. 4A). Thus, this cell line was chosen initially to examine the transcriptional effects of $\mathrm{Zn}-15$. As shown in Figure 9A, transfection of $\mathrm{Zn}-15$ was able to stimulate transcription from constructs containing either one copy of the GH Z box fused to a minimal prolactin promoter or one copy of the $\alpha M H C T_{3} R E$ fused to the herpes sim-
A

GH Z BOX

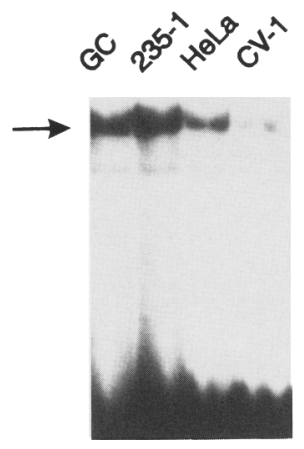

B
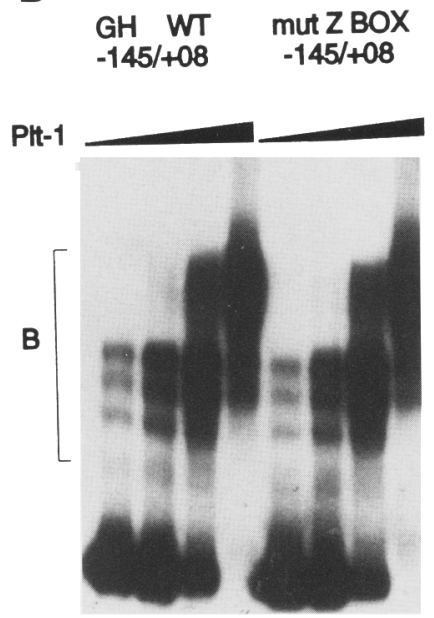

Figure 4. Analyses of the GH-Z-box binding activity in pituitary and nonpituitary cell types and Pit-1 binding to the GH promoter containing a mutated $\mathrm{GH} \mathrm{Z}$ box. $(A)$ EMSA assays of GH Z-box binding activity present in several pituitary and nonpituitary cell lines. A ${ }^{32}$ P-labeled GH Z-box element was used as a probe for $10 \mu \mathrm{g}$ of cell extracts prepared in parallel from rat pituitary somatotroph $(\mathrm{GC})$, lactotroph (235-1), human cervical carcinoma (HeLa), and African green monkey kidney cells (CV1). The arrow indicates the band shift. $(B \mid$ Comparison of Pit- 1 binding to the wild-type $\mathrm{GH}$ promoter and the $\mathrm{GH}$ promoter with a GH Z box mutation. ${ }^{32} \mathrm{P}$-Labeled $\mathrm{GH}$ promoter fragments containing both Pit-1-binding sites and the GH $\mathrm{Z}$ box, spanning from -145 to +08 relative to the start of transcription in the wild-type promoter $(\mathrm{GH} \mathrm{WT})$, and the mutated $\mathrm{GH} \mathrm{Z}$ box $(-110 /-95)$ (mut $\mathrm{Z} \mathrm{BOX}$ ) in the identical context were used as probes in EMSA assays with bacterially expressed Pit-1 diluted either $1: 10,1: 5,1: 2$ or $1: 1$, as described in Materials and methods. (B) Bound probe. 
I

II

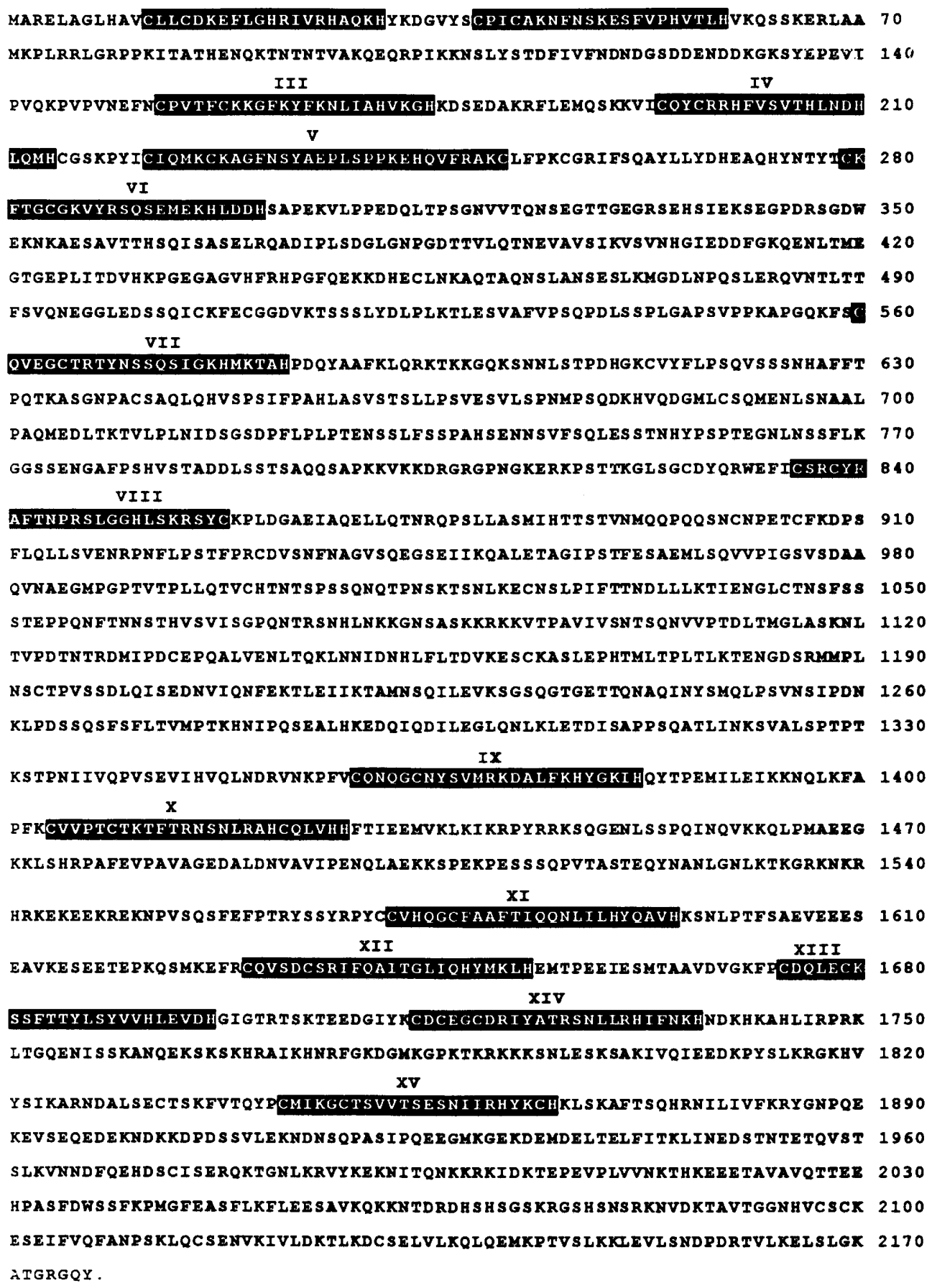

Figure 5. $\mathrm{Zn}-15$ cDNA amino acid sequence. Each of the 15 putative Cys $\mathrm{X}_{2-4} \mathrm{Cys}_{11-16} \mathrm{His}_{3-6}$ His zinc fingers are numbered and reverse highlighted.

plex thymidine kinase (TK) promoter. A Zn-15 deletion mutant (Zn-15 $\Delta 1-855)$ eliminating the amino-terminal zinc finger cluster also efficiently stimulated transcription from the GH Z box, whereas an additional aminoterminal truncation mutant (Zn-15 $\Delta 1-1214)$ stimulated transcription from this site but not as effectively as the wild-type $\mathrm{Zn}-15$. In contrast, a carboxy-terminal Zn-15 mutant truncated before the DNA-binding domain $(\mathrm{Zn}$ -
$15 \Delta 1215-2177)$ was transcriptionally inert, as was the isolated Zn-15 DNA-binding domain (Zn-15 DBD) (Fig. 9A).

We then examined the effects of $\mathrm{Zn}-15$ and Pit- 1 on the GH promoter. Previously, in transient transfection analyses, Pit-1 has been shown to strongly activate the $\mathrm{GH}$ and PRL promoters in HeLa cells (Ingraham et al. 1988). Surprisingly, in CV-1 cells, transfection of Pit-1 could produce only weak activation of the proximal 320 
Figure 6. Zn-15 protein and mRNA expression. (A) Schematic diagram of the $\mathrm{Zn}$ 15 cDNA-coding sequence. Vertical lines depict individual putative zinc fingers. $(B)$ Alignment of $\mathrm{Zn}-15$ putative zinc fingers. The conserved cysteine and histidine residues in each zinc finger are reverse highlighted. Amino acids that are not consistent with zinc finger consensus residues at their respective positions are circled. The three zinc fingers that are critical for binding to the $\mathrm{GH} \mathrm{Z}$ box (see Fig. 7) are lightly shaded. $(C)$ Comparison of endogenous somatotroph $\mathrm{Zn}-15$ protein and in vitrotranslated Zn-15 SDS-polyacrylamide gel migration. Ten micrograms of GC cell nuclear extract and $4 \mu \mathrm{l}$ of ${ }^{35} \mathrm{~S}$-labeled in vitro-translated $\mathrm{Zn}-15$ cDNA (TnT System, Promegal were run on a $5 \%$ SDSpolyacrylamide gel. The gel was transferred to nitrocellulose, and the lane containing the GC cell nuclear extract was probed with an antibody directed against the carboxyl terminus of $\mathrm{Zn}-15(\alpha \mathrm{Zn}-15)$ and visualized with a chemiluminescent secondary antibody (ECL, Amersham). The lane containing the ${ }^{35} \mathrm{~S}$-labeled in vitro-translated Zn-15 (Zn-15 I.V.T.) was exposed directly to film. Protein molecular weight markers are indicated. $(D)$ RNA blot of GC somatotroph cell mRNA. Twelve micrograms of denatured size-fractionated poly $(\mathrm{A})$-selected mRNA was transferred to nitrocellulose and probed with a random-primed 1-kb PvuII fragment from the Zn-15 carboxyl terminus. mRNA size standards (in $\mathrm{kb}$ ) are indicated at left. (E) RNase protection panel of Zn-15 expression. A ${ }^{32}$ P-labeled antisense cRNA probe from the Zn-15 DNA-binding domain was incubated with $20 \mu \mathrm{g}$ of total RNA from rat pituitary, testes, heart, spleen, liver, muscle, and kidney. A rat actin antisense cRNA probe was used to normalize the quality and quantity of RNA added to each reaction. The arrow indicates the size of the protected probe ( $863 \mathrm{bp}$ ). Size standards are indicated at right. (tRNA) Yeast transfer RNA control; (actin) rat $\beta$-actin probe.

bp of the rat GH promoter (Fig. 9B). In the same experiments, transfection of a Pit-1 cDNA strongly stimulated expression (74-fold) of the rat prolactin distal enhancer and proximal promoter (data not shown). On the GH promoter, transfection of $\mathrm{Zn}-15$ also activated expression weakly. Interestingly, when both Pit-1 and Zn-15 were cotransfected, the $\mathrm{GH}$ promoter was stimulated by an amount greater than the multiplicative product of their separate folds of activation. No synergism was observed when Pit-1 and Zn-15 were cotransfected with the $\mathrm{GH}$ promoter containing a mutated $\mathrm{GH} \mathrm{Z}$ box. Similar results were obtained in another cell line of macrophage origin (U937) (data not shown).

The mechanisms underlying transcriptional synergism are poorly understood. To determine whether synergism requires only transcription factor binding or whether both factors must also be transcriptionally competent, we tested several deletion mutants of $\mathrm{Zn}-15$ and Pit-1 for their ability to synergize with each other on the
GH promoter. Truncation of the amino-terminal zinc finger cluster (Zn-15 $\Delta 1-855)$ did not appreciably affect the ability of $\mathrm{Zn}-15$ to trans-activate or synergize with Pit-1 (Fig. 10A). A further amino-terminal deletion ( $\mathrm{Zn}$ $15 \Delta 1-1214$ ) decreased, but did not abolish, both transactivation and synergism with Pit-1 (Fig. 10A). However, a Zn-15 fragment containing only the carboxy-terminal zinc finger cluster (Fig. 10A, Zn-15 DBD) was incompetent for both trans-activation from the GH Z box sequence and synergism with Pit-1. While these results are in concordance with a model in which the DNA-binding domain and carboxyl terminus of $\mathrm{Zn}-15$ contain sufficient information for both trans-activation and synergistic interactions with Pit- 1 , we have not formally excluded the possibility that the ratios of trans-activation and synergism functions of the various $\mathrm{Zn}-15$ deletion mutants may reflect different levels of expression in the nucleus. To determine which regions of Pit-1 are required for synergism with $\mathrm{Zn}-15$, a series of Pit-1 amino 
A

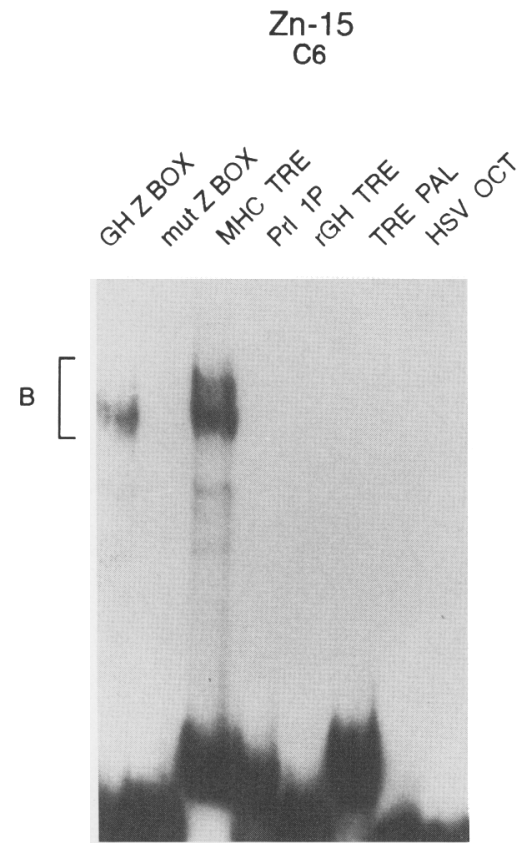

B

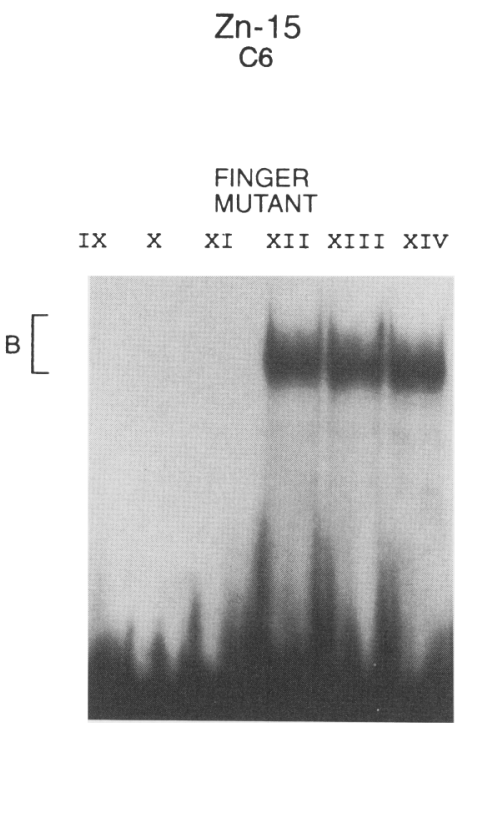

C

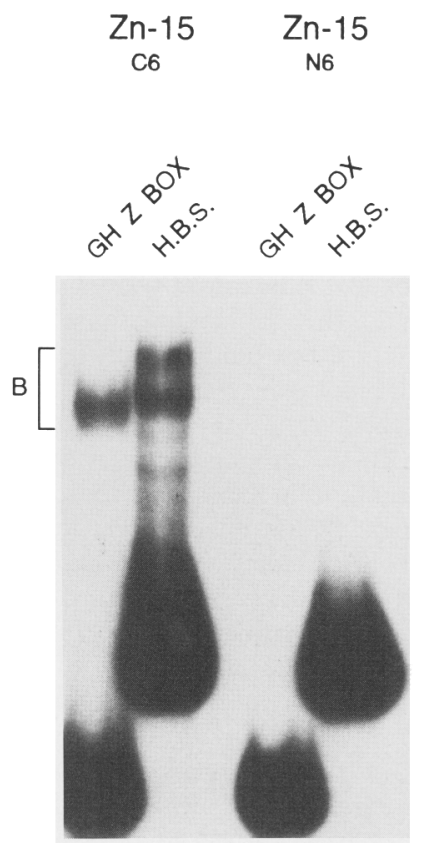

Figure 7. Analyses of Zn-15 DNA-binding activity. (A) EMSA assay of the Zn-15 carboxy-terminal zinc finger cluster binding specificity. ${ }^{32}$ P-Labeled sites encompassing the sequences of the GH Z box (GH Z BOX), mutated GH Z box (mut $Z$ BOX), $\alpha$-myosin heavy chain $T_{3}$ response element (MHC TRE), PRL Pit-1-binding site (Prl 1P), rat GH $T_{3}$ response element (rGH TRE), palindromic $T_{3}$ response element (TRE PAL), and herpes simplex virus octamer-binding site (HSV OCT) were used as probes for bacterially expressed $\mathrm{Zn}-15$ carboxy-terminal zinc finger cluster $(\mathrm{Zn}-15 \mathrm{C}$ (6) $(\mathrm{B})$ Mutational analysis of $\mathrm{Zn}-15$ zinc finger binding to the GH Z box. The first conserved histidine residue in each of the six Zn-15 carboxy-terminal cluster zinc fingers (fingers IX-XIV) was altered separately to a serine residue by conventional mutagenesis. Each of these six point mutants was expressed in bacteria in the context of the whole Zn-15 carboxy-terminal zinc finger cluster and analyzed for GH Z box-binding ability. (C) EMSA of the Zn-15 amino-terminal zinc finger cluster. The bacterially expressed amino-terminal zinc finger cluster (Zn-15 N6) and carboxy-terminal cluster were tested for binding to a ${ }^{32} \mathrm{P}$-labeled probe consisting of completely degenerate $16-\mathrm{mers}$ representing all possible binding sites [(H.B.S.) heterogenous binding sites] and the GH Z box. Approximately equal amounts of Zn-15 N6 and Zn-15 C6 protein were added to the binding reaction (data not shown). Three times the amount of cpm for the heterogeneous binding site oligonucleotide compared with the homogenous $\mathrm{Z}$ box gel shift probe was incubated with the bacterial protein extract, because only a fraction of the probe sequences would be expected to function as potential binding sites.

acid substitution mutants were constructed and functionally evaluated in transfection. A transcriptionally incompetent Pit-1 molecule consisting of the POU homeo domain and the carboxyl terminus ( $\Delta \mathrm{N}$ Pit-1) is unable to synergize with $\mathrm{Zn}-15$, as is a second transcriptionally incompetent Pit-1 mutant protein containing a proline for alanine substitution in the POU domain that causes hereditary dwarfism in humans (Pit-1 A158P; Pfäffle $\mathrm{e}^{+}$ al. 1992) (Fig. 10B).

\section{Discussion}

On the basis of the analysis of mouse and human dwarfs who carry Pit-1 genomic mutations, Pit-1 is clearly required for GH gene activation. Yet, the actions of other transcription factors are also necessary for activation of Pit-1 target genes. For example, Pit-1 does not effectively activate the prolactin distal enhancer, in the absence of ligand-bound estrogen receptor (Day et al. 1990; Sim- mons et al. 1990). Similarly, Pit-1 synergizes with ligandbound retinoic acid receptor on the Pit-1 gene enhancer (Rhodes et al. 1993). Here, we describe a new sequence conserved among hominid and quadruped GH romoters that constitutes an important element in regulating $\mathrm{GH}$ expression. By transgenic mouse analyses we show that the GH $\mathrm{Z}$ box, the binding site for $\mathrm{Zn}-15$, constitutes a crucial regulatory element because its mutation decreases transgene expression $>100$-fold. These data, coupled with the observation that $\mathrm{Zn}-15$ represents a major binding activity to this site, suggest that this factor may be an important component of GH gene expression. In concert with this model, $\mathrm{Zn}-15$ is capable of synergizing with Pit-1 in GH gene activation in heterologous cells in which Pit-1 alone produces only ineffective stimulation.

The molecular mechanisms by which transcription factors synergize are not well defined. In some cases, transcriptional synergism appears to reflect cooperative DNA-binding interactions (Jiang and Levine 1993). How- 
A

Figure 8. Analysis of $\mathrm{Zn}$-15-binding site interactions. $(A)$ Methylation interference analysis of GC cell extract and Zn-15 binding to the GH Z box. Methylated guanine residues in the ${ }^{32} \mathrm{P}$-labeled sense or antisense $\mathrm{GH} \mathrm{Z}$ box-binding site that interfere with binding by either $5 \mu$ l of GC cell extract (GC) or $4 \mu$ l of bacterially expressed $\mathrm{Zn}-15$ carboxy-terminal zinc finger cluster protein $(\mathrm{Zn}-15)$ are indicated by arrowheads. $(\mathrm{F})$ Methylated free $\mathrm{GH} \mathrm{Z}$ box probe; (B) bound $\mathrm{GH} Z$ box probe. $(B)$ Summary of $\mathrm{GH} \mathrm{Z}$ box methylation interference analysis. Arrowheads indicate guanine residues that interfere with $\mathrm{Zn}-15$ binding. (C) Alignment of $\mathrm{GH} \mathrm{Z}$ box and $\alpha$-MHC $\mathrm{TR}_{3}$ E-binding sites for $\mathrm{Zn}-15$. In each position, residues that are shared for both binding sites are reverse highlighted. (D) Antibody-perturbed somatotroph cell (GC) nuclear extract binding to the $\mathrm{GH} \mathrm{Z}$ box. Three microliters of GC cell nuclear extract was preincubated with $2 \mu \mathrm{l}$ of either preimmune sera or antisera reactive against $\mathrm{Zn}-15$ and subsequently used in EMSA assays with a ${ }^{32} \mathrm{P}$-labeled GH Z box probe. The arrow indicates the major GC cell nuclear extract/GH $\mathrm{Z}$ box complex. (GC NE) GC cell nuclear extract; (Pre I) preimmune sera; $(\alpha Z n-15)$ anti-Zn-15 antisera; $(+)$ addition of sera; $(-)$ no sera added.

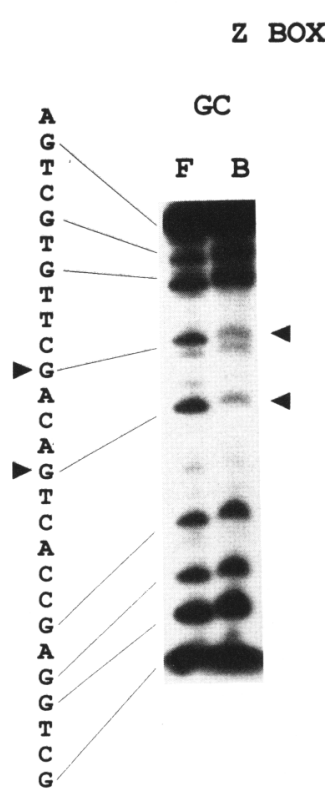

B

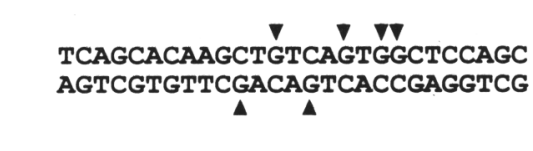

C

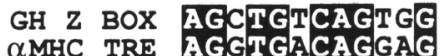

z BOX S

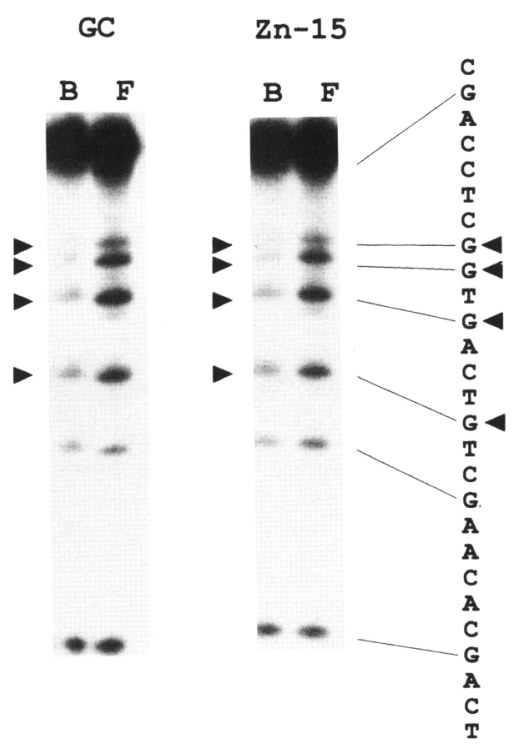

D

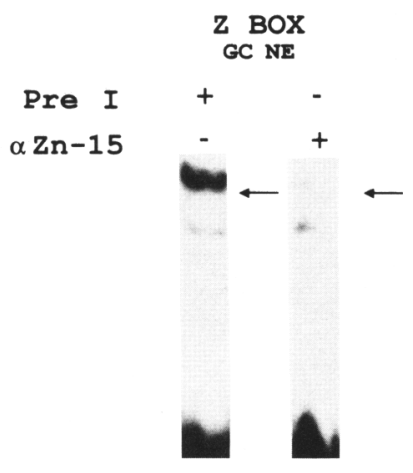

ever, this does not appear to be the case for $\mathrm{Zn}-15$ and Pit-1, as in EMSA studies we can detect no cooperativity in DNA binding between Pit-1 and the bacterially expressed Zn-15 carboxyl terminus (data not shown). Synergy requires that both proteins be trans-activationally competent, and for Pit-1 the amino acid sequences required are distinct from those necessary for synergism with the estrogen receptor in the activation of the prolactin distal enhancer (J. Holloway, in prep.), an observation that has intriguing implications with respect to cell type-specific expression of the GH and PRL genes.

\section{$\mathrm{Zn-15}$ is a novel member of the Cys/His zinc finger gene family}

The structural aspects of $\mathrm{Zn-15}$ may be informative in the study of other members of the zinc finger superfamily of transcription factors. We have found that fingers IX, X, and XI cooperate to form a unitary DNA-binding domain. Intriguingly, the linker sequences between these three fingers (21 and 143 amino acids, respectively) are much longer than the canonical 7 amino acid linkers observed to space zinc fingers in tandem arrays in all other members of this gene family in which DNA binding has been directly tested. Therefore, under the appropriate circumstances, widely spaced zinc fingers can cooperate in DNA binding. Previously, binding site selection (SAAB) studies with the Drosophila CF2 gene had suggested that zinc fingers separated by long linker sequences were unable to contribute to binding site recognition (Hsu et al. 1992). In our studies of Zn-15 DNAbinding specificity, we have found that $\mathrm{Zn}-15$ can bind to the $\alpha$ MHC $T_{3} R E$. Alignment of these two sequences shows that they have a high degree of base pair identity over the area with which $\mathrm{Zn}-15$ interacts with guanine residues. Intriguingly, in the $\alpha M H C T_{3} R E$, the $\mathrm{Zn}-15$ binding site overlaps with bases contacted by $T_{3}$ receptor/RXR heterodimers, and in EMSA analysis $\mathrm{Zn}-15$ can compete for binding with $\mathrm{T}_{3}$ receptor/RXR heterodimers (A. Näär, unpubl.). These data suggest that $\mathrm{Zn}-15$ is ca- 
A

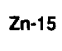

Zn-15

$\mathrm{Zn}-15 \Delta 1-855$

$\mathrm{Zn}-15 \Delta$ 1-1214

$\mathrm{Zn-15} \Delta \mathbf{1 2 1 5 - 2 1 7 7}$

Zn-15 DBD

$2 n-15$

Zn-15
FOLD INDUCTION

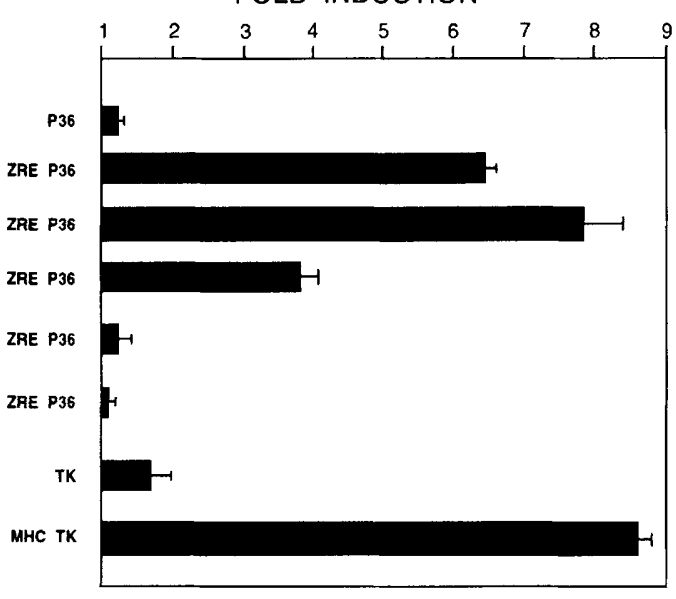

B

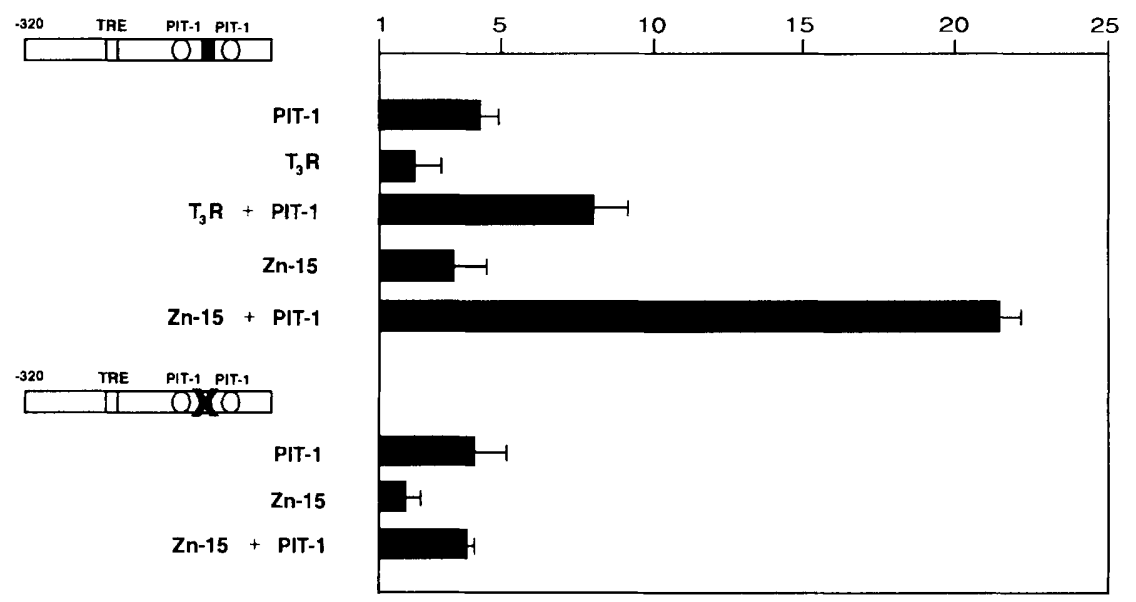

Figure 9. Transient transfection analyses of $\mathrm{Zn}-15$ transcriptional activity in CV-1 cells. (A) Stimulation of transcription by $\mathrm{Zn}-15$ and $\mathrm{Zn-15}$ deletion mutants from the GH $\mathrm{Z}$ box and $\alpha$-MHC $\mathrm{T}_{3}$ REs. Expression plasmids encoding $\mathrm{Zn}-15$ or $\mathrm{Zn}-15$ deletion mutants under the control of the RSV promoter (Simmons et al. 1990) were cotransfected with a luciferase cDNA under the control of the PRL minimal promoter $(\mathrm{P} 36)$, one copy of the GH Z box in front of the PRL minimal promoter (ZRE P36), the HSV TK promoter (TK), or one copy of the $\alpha-\mathrm{MHC} \mathrm{T}_{3} \mathrm{RE}$ in front of the TK promoter (MHC TK). Background was determined by using an RSV expression vector driving the expression of a gene encoding neomycin resistance (RSV Neo) (see Materials and Methods). Results are the average of triplicate determinations, and error bars represent S.E.E. Similar results were obtained in four experiments of similar design. (Zn-15 $\Delta 1-855)$ Zn-15 carboxy-terminal coding fragment deleting the first 855 amino acids; (Zn-15 $\Delta 1-1214)$ Zn-15 carboxy-terminal coding fragment deleting the first 1214 amino acids; (Zn-15 $\Delta 1215-2177$ ) $\mathrm{Zn}-15$ amino-terminal coding fragment deleting the carboxy-terminal 963 amino acids; (Zn-15 DBD) Zn-15-coding fragment spanning amino acids 1214-1753. (B) Cooperative interactions of $\mathrm{Zn}-15$ and Pit- 1 on the $\mathrm{GH}$ promoter and lack of cooperativity on the GH promoter containing a mutated $Z$ box. Transfections were performed as in (A) (also see Materials and methods). Transfections were balanced with RSV Neo so that the same amount of plasmid DNA was added to each plate of cells. $\left(T_{3} R\right)$ human $\beta$ thyroid hormone receptor. pable of modulating the responsivity of a subset of $T_{3}$ receptor target genes.

The role of the other 12 putative zinc finger sequences in the $\mathrm{Zn}$-15-coding sequence that do not participate in $\mathrm{GH} \mathrm{Z}$ box or $\alpha M H C \mathrm{~T}_{3} \mathrm{RE}$ binding is not entirely clear. Given the widespread distribution of Zn-15 mRNA and protein, these fingers might be involved in binding to other gene promoters. We have been unable to demonstrate any capacity for DNA binding of the first six amino-terminal zinc fingers. However, it is still possible that sequences exist to which these zinc fingers bind that we could not detect in our assay. In the CF2 zinc finger protein, a similar inability of amino-terminal zinc fingers to bind DNA specifically has also been observed (Gogos et al. 1992). Recently, basic amino acid sequences adjacent to zinc fingers have been shown to influence finger/DNA interactions (Keller and Maniatis 1992). It is thus possible that adjacent sequences necessary for specific DNA binding are lacking in both Zn-15 and CF2 amino-terminal fingers. Alternatively, zinc fingers have been demonstrated to bind to specific secondary struc- tures of of RNA (Theunissen et al. 1992), and it is possible that the $\mathrm{Zn}-15$ amino-terminal group of zinc fingers might subserve such a function. The observation that $\mathrm{Zn}-15$, a novel member of the zinc finger transcription factor superfamily (Rhodes and Klug 1993), binds to an evolutionarily conserved GH promoter sequence required for effective activation of this promoter in vivo raises intriguing questions about the role of this protein in development. Previously, several DNA-protein-binding activities on the $\mathrm{GH}$ promoter were characterized, and $\mathrm{Zn-15}$ is likely to correspond to a binding activity referred to as GHF-5 (Schaufele et al. 1990).

In conclusion, $\mathrm{Zn}-15$ is a novel zinc finger protein that binds to an evolutionarily conserved sequence in the GH gene required for effective Pit-1-dependent activation of this promoter in vivo and is capable of synergizing with Pit- 1 in experiments in cultured cells. These observations may help to define the combinatorial code that underlies the molecular basis of somatotroph and lactotroph-specific gene transcription during mammalian organogenesis. 
Lipkin et al.

A

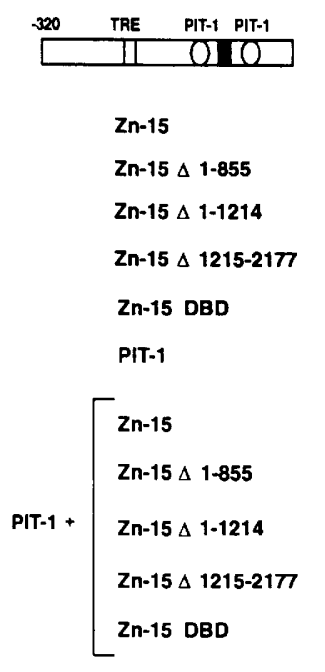

B

Figure 10. Deletional analysis of regions of $\mathrm{Zn}-15$ and Pit-1 necessary for synergistic interactions on the $\mathrm{GH}$ promoter. $(A)$ Mapping of $\mathrm{Zn}-15$ domains necessary for synergism with Pit-1. Transfections were performed as in Fig. 9. Transfections were balanced with RSV Neo so that the same amount of plasmid DNA was added to each plate of cells. $(B)$ Mapping of Pit-1 domains necessary for synergism with $\mathrm{Zn}$ 15. $(\Delta \mathrm{N}$ Pit-1) Deletion mutant of Pit-1 lacking the amino-terminal trans-activation domains (Ingraham et al. 1988). (Pit-1 A158P) Pit-1 mutant containing a proline for alanine substitution at amino acid 158 in the POU-specific domain (Pfäffle et al. 1992).

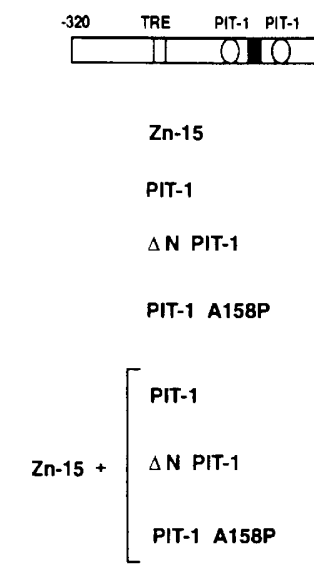

\section{Materials and Methods}

Cloning of $\mathrm{Zn}-15$

A multimerized $Z$ box sequence $\left(5^{\prime}\right.$-AATTCAGCACAAGCTGTCAGTGGAATT-3') was used to screen rat pituitary GC cell $\lambda \mathrm{gt} 11$ expression libraries as described previously (Ingraham et al. 1988|. Multiple overlapping clones were isolated from rat pituitary and lactotroph cell line (MMQ) cDNA libraries. A large number of oligonucleotides were synthesized to sequence the full Zn-15 ORF (Sequenase, U.S. Biochemical).

Bacterial and reticulate lysate expression of $\mathrm{Zn}-15$, antibody generation, and Western analysis

For in vitro translation, the full $\mathrm{Zn}-15$ cDNA was subcloned into the vector pCITE $2 \mathrm{a}$ (Novagen) and translated in the presence of $\left[{ }^{35} S\right]$ methionine using the TnT System-coupled transcription and translation system (Promega), with the addition of $100 \mathrm{mM} \mathrm{KCl}$ to enhance full-length translation.

A 1.6-kb coding fragment containing zinc fingers IX-XIV [Zn$15 \mathrm{C6}$; $\mathrm{XbaI}$ (nucleotide 3642)/MscI (nucleotide 5259)] and a
1.7- $\mathrm{kb}$ coding fragment containing zinc fingers I-VI [Zn-15 N6; BamHI (nucleotide -6)/PstI/(nucleotide 1768)] were expressed as glutathione $S$-transferase (GST) fusion protein according to standard protocols (Pharmacia). For the generation of antisera reactive against $\mathrm{Zn}-15$, the carboxyl terminus of $\mathrm{Zn}-15$ (133 amino acids) was also expressed as a GST fusion protein and purified over glutathione-agarose (Sigma). GST Zn-15 carboxyl terminus fusion protein was excised from protein gels, emulsified with RIBI adjuvant, and injected into white, female New Zealand rabbits. Antisera used in this manuscript are all from the third bleed. For Western analysis, GC and 235-1 cell nuclear extracts were made as described previously (Dignam et al. 1983), with the addition of extra protease inhibitors $14 \mathrm{mM}$ PMSF, 2 $\mathrm{U} / \mathrm{ml}$ of antipain, $2 \mathrm{U} / \mathrm{ml}$ of leupeptin, $2 \mathrm{U} / \mathrm{ml}$ of aprotinin, 4 $\mathrm{mm}$ benzamidine) to staunch $\mathrm{Zn}-15$ protein degradation. Blots were incubated with $1: 1000$ dilution of antisera under the manufacturer's suggested protocol for the ECL Western Blot Kit (Amersham).

EMSA, antibody perturbation, and methylation interference Double-stranded oligonucleotides encoding the $\mathrm{GH} \mathrm{Z}$ box 
(5'-AATTCAGCACAAGCTGTCAGTGGCACCAATT-3'), rat $\alpha M H C \quad T_{3} R E \quad\left(5^{\prime}\right.$-TTGGTCTGGAGGTGAGGCAAGGACAG$\left.3^{\prime}\right)$, mutated $Z$ box (5'-AATTCCTACACCTAGTGACTGTTCACCAATT-3'), rat PRL 1P Pit-1-binding site (Prl 1P; $5^{\prime}$-GCATGCTAATGATATTCTTT-3'), herpes simplex virus octamer-binding site (HSV OCT; 5'-CCTGATTATATATATATTCATGAAGGTG- $3^{\prime}$ ), rat GH $\mathrm{T}_{3}$ RE (5'-AAGGGGATCCTAAGGTAAGATCAGGGACGTGACCGCAGGAGATCT$\left.3^{\prime}\right)$, or palindromic $T_{3} R E$ (5'-AAGGGGATCCGTAAGATTCAGGTCCATGACCTGAGGAGA-3'), 16-mer heterogenous binding site oligomer was prepared as described previously (Drolet et al. 1991). One to four microliters of GC, 235-1, HeLa, or CV-1 cell line nuclear extract or bacterially expressed protein extract was used in EMSA assays as described previously (Drolet et al. 1989|. For antibody perturbation experiments, GC nuclear extracts were preincubated with preimmune sera or $\mathrm{Zn}-15$ antisera for $1 \mathrm{hr}$ before addition of labeled DNA-binding site probe. For methylation interference analysis, $4 \mu$ l of GC nuclear extract or $6 \mu$ lof GST Zn-15 C6 was used in a preparative gel shift as described previously (Drolet et al. 1991).

\section{Generation of transgenic mice}

Plasmid pGH320-hGH was constructed by fusing the proximal $320 \mathrm{bp}(-310$ to +8 rat $\mathrm{GH})$ of the rat $\mathrm{GH}$ promoter to the genomic hGH gene (Nicholls Institute, San Juan Capistrano, CA). Plasmid pGH320 GH Z box Mut-hGH was similarly constructed, except that the $\mathrm{GH} \mathrm{Z}$ box sequence had been transverted by conventional mutagenesis, as described in EMSA methods. The rat $\mathrm{GH}$ promoter/hGH structural gene fusion DNA was purified and injected $(1-5 \mu \mathrm{g} / \mathrm{ml})$ into mouse oocytes as described previously (Lira et al. 1988). All transgenic lines further characterized were shown to carry intact copies of the transgene as determined by Southern analysis.

\section{hGH reporter gene quantification in transgenic mice}

Immunoquantitation of transgenic mouse pituitary hGH was peformed as described previously (Lira et al. 1988).

\section{Transfection analyses}

Reporter plasmid vectors containing rat GH promoter information $(-310$ to +8$)$, rat $\mathrm{GH}$ promoter with mutated $-159 /-148$ site $\left(5^{\prime}\right.$-TCTACTGTTTTC-3') $-142 /-130 \quad\left(5^{\prime}\right.$-GTGTGTTTCTTCT-3') site, or GH Z box sequences (see legend to Fig. 1 and EMSA methods above), rat PRL 5 '-flanking information $(-1831$ to $-1530 /-178$ to +36$)$; or the GH Z box $\left(5^{\prime}\right.$-TCAGCACAAGCTAGCAGTGGCACC-3') fused to a minimal prolactin promoter $(-36$ to +8$)$ or rat $\alpha-\mathrm{MHC} \mathrm{T}_{3} \mathrm{RE}\left(5^{\prime}\right.$-TTGGTCTGGAGGTGACAGGAGGACAGGTT-3') fused to the herpes simplex TK promoter were prepared as described previously (Simmons et al. 1990). Expression plasmids for Pit-1 were under control of the cytomegalovirus (CMV) promoter region and have been described previously (Ingraham et al. 1988). Expression plasmids for $\mathrm{Zn}-15, \mathrm{~T}_{3} \beta$ receptor, or a control plasmid containing a gene encoding neomycin resistance (Neo) were under control of the Rous sarcomavirus (RSV) promoter (Simmons et al. 1990). CV-1 cells at a density of $0.5 \times 10^{6}$ cells per plate were transfected by calcium phosphate precipitation with $1 \mu \mathrm{g}$ of luciferase reporter plasmid, and, as indicated, $1 \mu \mathrm{g}$ of CMV Pit1, CMV Pit-1 A158P, and CMV $\Delta N$ Pit-1 or $3 \mu \mathrm{g}$ of RSV $T_{3} \beta$

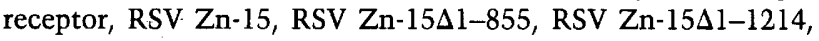
and RSV Zn-15 1215-2177. More Zn-15-containing plasmid DNA was used because the $\mathrm{Zn}$-15-coding sequence $(6.55 \mathrm{~kb})$ is larger than the entire RSV expression vector $(3.9 \mathrm{~kb})$. Twenty- four hours post-transfection, cells were washed with serum-free DME, incubated in $3 \mathrm{ml}$ of DME containing $10 \%$ charcoalstripped serum (Scantibodies Laboratories), and cells were harvested and luciferase activity was assayed on the following day as described previously (Drolet et al. 1989).

\section{Plasmid construction}

For generation of the zinc finger IX-XIV DNA-binding mutants, the first conserved histidine residue and the preceding amino acid were replaced by a glycine and a serine residue (BamHI site) by conventional mutagenesis (T7 Polymerase MutaGene, BioRad). Zn-15 $\Delta 1-855$ was constructed by excising a BglII (nucleotide 2565)/XbaI (3' polylinker) fragment from pCITE2a Zn-15, which was inserted into an RSV expression vector. Similarly, RSV Zn-15 $151-1214$ was constructed by subcloning a Zn-15 $X b a I$ (nucleotide 3642)/XbaI (3' polylinker)-coding fragment into the same vector. RSV Zn-15 1215-2177 was constructed by cutting RSV Zn-15 with $\mathrm{XbaI}$, which excised all coding sequences beyond nucleotide 3560 , and religating.

\section{In situ hybridization analysis}

In situ hybridization with $10-\mu \mathrm{m}$ sagittal sections of adult transgenic mouse anterior pituitary glands was performed essentially as described previously (Aubry et al. 1993) with oligonucleotides from the 3 '-untranslated sequences of either mouse (5'-GGGGCAGGGAGGCACAGGAGAGTGCAGCAGAGACACTGGTGAGTGGCTA-3') or human (5'-TAGGACAAGGCTGGTGGGCACTGGAGTGGCAACTTCCAGGGCCAGGAGAGG-3') GH mRNAs.

\section{Acknowledgments}

We gratefully acknowledge Dr. J. Voss and B. McEvilly for construction of the original GH promoter mutants, C. Nelson for invaluable assistance with tissue culture, G. DiMattia for assistance with analyses of transgenic mice, L. Erkman and P. Sawchenko for assistance with in situ analysis, H. Mangalam for computer analysis, and Drs. B. Andersen and C. Glass for critical reading of this manuscript. M.G.R. is an investigator with the Howard Hughes Medical Institute. These studies were supported in part by a grant from the National Institutes of Health (DK18477).

The publication costs of this article were defrayed in part by payment of page charges. This article must therefore be hereby marked "advertisement" in accordance with 18 USC section 1734 solely to indicate this fact.

\section{Note added in proof}

The $\mathrm{Zn}-15$ nucleotide sequence has been submitted to the GenBank data library.

\section{References}

Aubry, J.-M., M.-F. Schulz, S. Pagliusi, P. Schulz, and J.Z. Kiss. 1993. Coexpression of dopamine $D_{2}$ and substance $P$ /Neurokinin-1) receptor messenger RNAs by a subpopulation of cholinergic neurons in the rat striatum. Neuroscience 53: $417-424$.

Bodner, M. and M. Karin. 1987. A pituitary-specific trans-acting factor can stimulate transcription from the growth hormone promoter in extracts of nonexpressing cells. Cell 50: 267275 . 
Bodner, M., J.L. Castrillo, L.E. Theill, T. Deerinck, M. Ellisman, and M. Karin. 1988. The pituitary-specific transcription factor GHF-1 is a homeobox-containing protein. Cell 55: 505518.

Brent, G.A., J.W. Harney, Y. Chen, R.G. Warne, D.D. Moore, and P.R. Larsen. 1989. Mutations of the rat growth hormone promoter which increase and decrease response to thyroid hormone define a consensus thyroid hormone response element. Mol. Endocrin. 3: 1996-2007.

Day, R.N., S. Koike, M. Sakai, M. Muramatsu, and R.A. Maurer. 1990. Both Pit-1 and the estrogen receptor are required for estrogen responsiveness of the rat prolactin gene. Mol. Endocrin. 4: 1964-1971.

Dignam, J.D., R.M. Lebovitz, and R. Roeder. 1983. Accurate transcriptional initiation by RNA polymerase II in a soluble extract from isolated mammalian nuclei. Nucleic Acids Res. 11: $1475-1489$.

Dolle, P., J.L. Castrillo, L. Theill, T. Deerinck, and M. Ellisman. 1990. Expression of GHF-1 protein in mouse pituitaries correlates both temporally and spatially with the onset of growth hormone gene activation. Cell 60: 809-820.

Drolet, D.W., K.M. Scully, D.M. Simmons, M. Wegner, K.T. Chu, L.W. Swanson, and M.G. Rosenfeld. 1991. TEF, a transcription factor expressed specifically in the anterior pituitary during embryogenesis, defines a new class of leucine zipper proteins. Genes \& Dev. 5: 1739-1753.

Evans, R.M., N.C. Birnberg, and M.G. Rosenfeld. 1982. Glucocorticoids and thyroid hormone transcriptionally regulate growth hormone gene expression. Proc. Natl. Acad. Sci. 79: 7659-7663.

Glass, C.K., R. Franco, C. Weinberger, V.R. Albert, R.M. Evans, and M.G. Rosenfeld. 1987. A c-erbA binding site in rat growth hormone gene mediates trans-activation by thyroid hormone. Nature 329: 738-741.

Gogos, J.A., T. Hsu, J. Bolton, and F.C. Kafatos. 1992. Sequence discrimination by alternatively spliced isoforms of a DNA binding zinc finger domain. Science 257: 1951-1954.

He, X., M.N. Treacy, D.M. Simmons, H.A. Ingraham, L.W. Swanson, and M.G. Rosenfeld. 1989. Expression of a large family of POU-domain regulatory genes in mammalian brain development [published erratum appears in Nature (1989) Aug. 24;340(6235):662]. Nature 340: 35-41.

Hsu, T., J.A. Gogos, S.A. Kirsh, and F.C. Kafatos. 1992. Multiple zinc finger forms resulting from developmentally regulated alternative splicing of a transcription factor gene. Science 257: 1946-1950.

Ingraham, H.I, R. Chen, H. Mangalam, H. Elsholtz, S. Flynn, C. Lin, D. Simmons, L. Swanson, and M.G. Rosenfeld. 1988. A tissue-specific transcription factor containing a homeodomain specifies a pituitary phenotype. Cell 55: 519-529.

Jiang, J. and M. Levine. 1993. Cooperative interactions with bHLH activators delimit threshold responses to the dorsal gradient morphogen. Cell 72: 741-752.

Keller, A.D. and T. Maniatis. 1992. Only two of the five zinc fingers of the eukaryotic transcriptional repressor PRDI-BF1 are required for sequence-specific DNA binding. Mol. Cell. Biol. 12: 1940-1949.

Lemaigre, F.P., D.A. Lafontaine, S.J. Courtois, S.M. Durviaux, and G.G. Rousseau. 1990. Sp1 can displace GHF-1 from its distal binding site and stimulate transcription from the growth hormone gene promoter. Mol. Cell. Biol. 10: 18111814.

Li, S., E.B. Crenshaw III, E.J. Rawson, D.M. Simmons, L.W. Swanson, and M.G. Rosenfeld. 1990. Dwarf locus mutants lacking three pituitary cell types result from mutations in the POU-domain gene pit-1. Nature 347: 528-533.
Lira, S.A., E.B. Crenshaw III, C.K. Glass, L.W. Swanson, and M.G. Rosenfeld. 1988. Identification of rat growth hormone genomic sequences targeting pituitary expression in transgenic mice. Proc. Natl. Acad. Sci. 85: 4755-4759.

Lira, S.A., K. Kalla, C. Glass, and M.G. Rosenfeld. 1993. Synergistic interactions between Pit-1 and other elements are required for effective somatotroph rat growth hormone gene expression in transgenic mice. Mol. Endocrinol. 7: 694-701.

Mangalam, H.J., V.R. Albert, H.A. Ingraham, M. Kapiloff, L. Wilson, C. Nelson, H. Elsholtz, and M.G. Rosenfeld. 1989. A pituitary POU domain protein, Pit-1, activates both growth hormone and prolactin promoters transcriptionally. Genes \& Dev. 3: 946-958.

Nelson, C., E.B. Crenshaw III, R. Franco, S.A. Lira, V.R. Albert, R.M. Evans, and M.G. Rosenfeld. 1986. Discreet cis-active sequences dictate the cell type-specific expression of rat prolactin and growth hormone genes. Nature 322: 557-562.

Nelson, C., V.R. Albert, H.P. Elsholtz, L.I. Lu, and M.G. Rosenfeld. 1988. Activation of cell-specific expression of rat growth hormone and prolactin genes by a common transcription factor. Science 239: 1400-1405.

Ohta, K., Y. Nobukuni, H. Mitsubuchi, S. Fujimoto, and I. Matsuda. 1992. Mutations in the Pit-l gene in children with combined pituitary hormone deficiency. Biochem. Biophys. Res. Commun. 189: 851-855.

Pavletich, N.P. and C. Pabo. 1991. Zinc finger-DNA recognition: Crystal structure of a Zif268-DNA complex at 2.1 angstrom. Science 252: 809-816.

Pfäffle, R.W., G.E. DiMattia, J.S. Parks, M.R. Brown, J.M. Wit, M. Jansen, H. Van der Nat, J.L. Van den Brande, M.G. Rosenfeld, and H.I. Ingraham. 1992. Mutation of the POU-specific domain of pit-1 and hypopituitarism without pituitary hypoplasia. Science 257: 1118-1120.

Radovick, S., M. Nations, Y. Du, L.A. Berg, B.D. Weintraub, and F.E. Wondisford. 1992. A mutation in the POU-Homeodomain of Pit-1 responsible for combined pituitary hormone deficiency. Science 257: 1115-1117.

Read, D. and J.L. Manley. 1992. Alternatively spliced transcripts of the Drosophila tramtrack gene encode zinc finger proteins with distinct DNA binding specificities. EMBO J. 11: 10351044.

Rhodes, S., R. Chen, G. DiMattia, K. Scully, K. Kalla, S. -C. Lin, V. Yu, and M.G. Rosenfeld. 1993. A tissue-specific enhancer confers Pit-1 dependent morphogen inducibility and autoregulation upon the Pit-1 gene. Genes \& Dev. 7: 913-932.

Rhodes, D. and A. Klug. 1993. Zinc fingers. Sci. Am. 268: 56-65.

Ruppert, J.M., B. Vogelstein, K. Arheden, and K. Kinzler. 1990. GLI3 encodes a 190-kilodalton protein with multiple regions of GLI similarity. Mol. Cell. Biol. 10: 5408-5415.

Schaufele, F., B.L. West, and T. Reudelhuber. 1990. Somatotroph and lactotroph specific interactions with the homeobox protein binding sites in the rat growth hormone gene promoter. Nucleic Acids Res. 18: 5235-5243.

Schaufele, F., B.L. West, and T. Reudelhuber. 1990. Overlapping Pit-1 and Spl binding sites are both essential to full rat growth hormone gene promoter activity despite mutually exclusive Pit-1 and Spl binding. I. Biol. Chem. 265: 1718917196.

Settleman, J., V. Narasimhan, L.C. Foster, and R.A. Weinberg. 1992. Molecular cloning of cDNAs encoding the GAP-associated protein p190: Implications for a signaling pathway from ras to the nucleus. Cell 69: 539-549.

Sharp, D.Z. and Y. Cao. 1990. Regulation of cell-type-specific transcription and differentiation of the pituitary. BioEssays 12(2): 80-85.

Simmons, D.M., J.W. Voss, H.A. Ingraham, J.M. Holloway, R.S. 
Broide, M.G. Rosenfeld, and L.W. Swanson. 1990. Pituitary cell phenotypes involve cell-specific Pit-1 mRNA translation and synergistic interactions with other classes of transcription factors. Genes \& Dev. 4: 695-711.

Tatsumi, K., K. Miyai, T. Notomi, K. Kaibe, N. Amino, Y. Mizuno, and H. Kohno. 1992. Cretinism with combined hormone deficiency cause by a mutation in the PIT1 gene. Nat. Genet. 1: 56-58.

Theunissen, O., F. Rudt, U. Guddat, H. Mentzel, and T. Pieler. 1992. RNA and DNA-binding zinc fingers in Xenopus TFIIIA. Cell 71: 679-690.

Voss, J. and M.G. Rosenfeld. 1992. Anterior pituitary development: Short tales from dwarf mice. Cell 70: 527-530.

Zhang, W., R. Brooks, D. Silversides, B.L. West, F. Leidig, J. Baxter, and N. Eberhard. 1992. Negative thyroid hormone control of human growth hormone gene expression is mediated by 3 -untranslated $/ 3^{\prime}$-flanking DNA. I. Biol. Chem. 267: 15056-15063. 


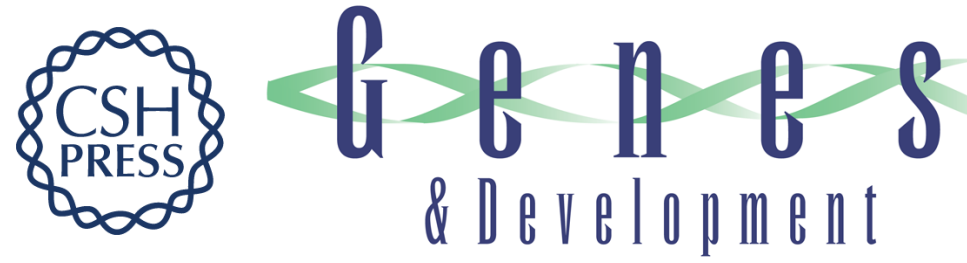

\section{Identification of a novel zinc finger protein binding a conserved element critical for Pit-1-dependent growth hormone gene expression.}

S M Lipkin, A M Näär, K A Kalla, et al.

Genes Dev. 1993, 7:

Access the most recent version at doi:10.1101/gad.7.9.1674

References This article cites 40 articles, 17 of which can be accessed free at: http://genesdev.cshlp.org/content/7/9/1674.full.html\#ref-list-1

License

Email Alerting Service

Receive free email alerts when new articles cite this article - sign up in the box at the top right corner of the article or click here.

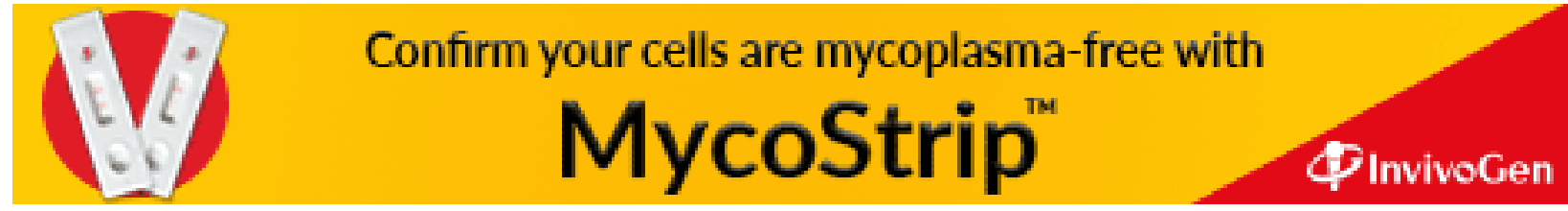

